\title{
Digital Audio Workstation in Music Self-Learning
}

\author{
(A Design Based Research)
}

\author{
Febbry Cipta* \\ Department of Music Education - FPSD \\ Universitas Pendidikan Indonesia \\ Bandung, Indonesia \\ *febbrycipta77@upi.edu
}

\begin{abstract}
The rapid development of information and communication technology has had a strong impact on the process of learning music. One impact that can be seen is that the teacher is no longer seen as the only source of information, but he is a guide for his students to access and manage their learning process. This article discusses how students of the Department of Music Education, Universitas Pendidikan Indonesia undertook the process of developing creativity and musical skills. Creativity and skills are two lovebirds that cannot be separated in musical activities. Through an approach to the activity of making music rearrangements, it can be seen that digital audio workstations (DAW), as artificial intelligence and machine learning, have motivated students and teachers in building the stages of music self-learning. By using a research-based design method, these stages consist of the problem analysis stage, the development of a problem-solving design based on relevant theories, the product evaluation and trial phase, and the reflection and documentation stage. The work steps in each stage are carried out collaboratively between researchers and students as practitioners which are based on objectives, optimization, and process efficiency. The data obtained from observations, interviews, and literature review which is then described qualitatively.
\end{abstract}

Keywords-music education, creativity, skill, digital audio workstation, rearrangements, computers, ICT

\section{INTRODUCTION}

The rapid development of information and communication technology (ICT) in this era of industrial revolution 4.0, has had a strong impact on the perspective of the music learning process. When viewed from the development of music learning creations and innovations, students no longer depend on the teacher for how their ideas can be expressed. The teacher may act as a guide for the student, namely a guide to access information and manage the learning process. However, the teacher is not the only source of information. Furthermore, the possible impacts that can be seen are, students or anyone can share widely their musical creations, be it your own work or an arrangement/music cover, and do not rule out if this activity can then be a source of income.

This article focuses on the use of digital audio workstations (DAW) in computer music learning, through the implementation of self-learning, in order to develop musical creativity. Many researchers have conducted studies on the topic of computer music and DAW, among others, Guo [1], Nart [2], and Arici [3]. As machine learning, DAW becomes one of the mediums which is used in the process of developing musical knowledge and abilities. Not only for students and teachers, it's for music creators in general. On the other hand, as artificial intelligence, DAW development is very possible and usable to represent ideas and musical expressions desired by users, both in terms of the diversity of instruments, as well as musical attributes including articulation, duration, dynamics, ornamentation, texture, etc.

In addition to studies on the development of ICT in the field of music education and learning, Researchers also seek to collect literature on topics of self-learning studies. As for the study of self-learning among them has been done by, Suardana [4], Ludovico and Mangione [5], Sukmono [6], Saripah and Santini [7], and Cipta [8], who in general have viewed that, self-learning is implemented as a strategy in an effort to repair, enhance, and maintain learning outcomes obtained by students from formal processes (in the classroom), so that the principle of learning completeness can be achieved optimally.

The focus of the study on DAWs is linked to self-learning, it can be said that there are no other researchers who have studied it. But even if this study is seen as not a new topic, presumably this study becomes a source that can add information for the development of music education in terms of ICT and self -earning. On the other hand, this study is relevant to the spirit of independent learning - independent campus (merdeka belajar - kampus merdeka/MBKM), based on the policies of the Ministry of Education and Culture Republik Indonesia 2020. Because for the author, the concept of MBKM must be built on the basis of independence and justice in learning, which is contained in the principle of self-learning.

This study departs from problems regarding student activities in completing their assignments in terms of, agreed deadlines, work ethic, and performance. A small proportion of students are able to show punctuality in submitting assignments accompanied by satisfactory performance (musical works). However, some others still cannot show this yet. Researchers have the opinion that students still do not understand how to implement self-learning (outside face to face class) in order to complete the assignment given. 
When referring to the semester credit unit (credits), selfstudy should be done for 60 minutes for one credit on a weekly basis in one semester (Regulation of the Minister of Education and Culture Republik Indonesia No. 3/2020 about Standar Nasional Pendidikan Tinggi). But in reality, not all students do this optimally. So that this phenomenon is important to understand together, both for lecturers and students, in order to achieve learning objectives.

\section{LITERATURE REVIEW}

Bloom [9] discusses the taxonomy of education that has been widely used by educators, namely cognition, affection, and psychomotor. This taxonomy is the basic principle of the ongoing and ongoing educational process. If reinforced by the opinion of Gordon [10] which discusses the stages of learning music, then cognition is built by the process of appreciation of music as an effort to build knowledge and understanding. Meanwhile, in an effort to develop affection, it is necessary to be closer to music that is familiar and favored by students in order to build enthusiasm for learning and practicing. As for psychomotor, through focused learning and training routines with material that is clear and easy for students to understand, will be able to develop student skills in conveying musical ideas.

Gagne [11] describes the concept of gifted as an ability that has existed since birth, and talents as performance that is influenced by the environment and inner spirit. This opinion is strengthened by, Sanjaya [12] who according to him, The musical performance shown by the students is the result of the learning process which in principle is supported by the gifted domain (gifts) and the talents domain (performance). So based on these two opinions, these domains are present in how a student demonstrates proficiency in operationalizing DAW, compiling and processing musical ideas, as well as in his learning spirit.

Referring to Gie [13] regarding the learning process which is carried out efficiently and thoroughly, so for the higher education level, the learning process is not sufficiently done formally in the classroom. However, self-learning activities are proponents who strongly contribute to the desired results. And according to Dembo [14], strategies and steps for self-learning for students are needed, through an approach self-management which covers, (1) self-evaluation and monitoring, (2) goal setting and strategic planning, (3) strategy implementation monitoring, and (4) strategy outcome monitoring.

\section{DESIGN BASED RESEARCH METHODS}

Implementation of a design based research model in this study is the researcher's effort to systematically construct a contextual framework between theory and practice. It aims to improve the learning process for Computer Music courses in the Music Education Department Universitas Pendidikan Indonesia. Alghamdi and $\mathrm{Li}$ [15] argues that design based research is built by analyzing problem activities, as well as developing and implementing designs (as a solution), conducted collaboratively by researchers and practitioners.

Refers to Herrington and Reeves [16], the study conducted by researchers was carried out through stages, namely, (a) in the first stage, researchers and practitioners collaboratively explore problems faced by students in the computer music lecture process. Then an illustration was obtained that it turned out that what became the constraint was the students understanding of their self-learning method. After that (b) in the second stage, the study activity is focused on designing a design in the form of self-learning that will be implemented as problem solving. At this stage, after conducting literacy tracing and relevant theories, researchers and practitioners formulate a strategy design and work steps for music selflearning.

Third phase (c), carry out testing and refinement of selflearning designs in the practice of Computer Music courses through repeated cycles. After the self-learning work step design is implemented, then researchers and practitioners perform data analysis in order to improve it to be implemented in the next cycle. Finally, the fourth stage (d), implementing improved self-learning strategies based on the evaluation of the cycles in the previous stage. After that researchers, practitioners, and students reflect in order to establish the principles of strategic design and self-learning work steps as a support in improving learning outcomes in Computer Music courses.

This research was conducted qualitatively, with data collection techniques through observation, interviews, questionnaires, and literature review. The data collection instruments used were a check list, a questionnaire, an interview guide, an observation guide, and a portable multifunction device, namely a cellphone/smartphone. With this tool, researchers can record audio, video, take pictures, record various phenomena, and search online for literacy sources needed.

Design validation is carried out internally. This activity involves practitioners and students by discussing relevant theories and the data obtained. The design of music selflearning strategies in the Computer Music course is built by work steps consisting of, (1) self-evaluation and monitoring related to the learning outcomes at each meeting, (2) goal setting and strategic planning related to the efforts that will be made in achieving learning objectives, (3) strategy implementation monitoring related to understanding the activity of making arrangements using DAW, and (4) strategy outcome monitoring relating to monitoring of results that have been achieved.

The design is implemented by students guided by lecturers, packaged through interesting, clear and structured activities, and is linked to the context of learning outcomes in the Computer Music course. 


\section{DISCUSSION}

\section{A. Identification and Analysis of Problems}

Activities in identifying and analyzing problems are carried out through observation, open interviews, review of literature, and questionnaires to students, who have and will take the Computer Music lecture process. So that through this activity an overview of the problem is obtained, in terms of facilities, both those owned by students and those provided by the department, can be said to be quite adequate. Although it seems that the facilities provided by the department need proper enrichment of the lecture hall, as well as increasing the number of computer units with specifications according to technological developments and the needs of lectures.

In terms of the amount of time provided for one class meeting, it is 100 minutes, which in one semester as many as 16 face to face. It should be understood that this course has two credits, it means that in one week the learning process in class is done twice 50 minutes equals 100 minutes, a structured assignment of twice 50 minutes equals 100 minutes, and selfstudy activities twice 60 minutes equal to 120 minutes. The time calculation provided can be said to be sufficient in an effort to study completeness in the Computer Music course.

Through an analysis of the questionnaire distributed to students, both those who have contracted and those who will contract this course, obtained a description that, the problems faced by students are in the work steps of their self-learning activities. Students are faced with difficulties in managing time in showing efforts to achieve the goals of each activity, and difficulty obtaining information to develop musical ideas using a DAW. So it is necessary to compile and implement selflearning designs through approaches to strategies and work steps.

\section{B. Design Making}

The self-learning strategies and work steps designed for this Computer Music course are adapted to Dembo [14]. Then this design is conveyed to students in face-to-face lectures at the first meeting. Lecturers and students collaboratively discuss each stage of work contained in the design. This is done as an effort to build harmony in understanding and develop the design itself. The results obtained from this activity are in the form of worksheets contains weekly learning objectives, preparation of the required time, and monitoring of learning outcomes. This worksheet becomes a kind of adaptive and flexible guide for students while carrying out their self-learning.

The preparation of the initial design was carried out collaboratively between the researcher and two music education lecturers as practitioner resource persons. This activity is carried out before entering the new semester lecture period. Researchers offer design ideas to practitioner resource persons for later analysis, reflection and revision. After the revision results are declared feasible to be implemented, the researchers compile them in a worksheet format accompanied by explanations that will be delivered to students at the first meeting at the beginning of the semester.

\section{DAW as a Medium for Developing Musical Creations}

The questionnaire used in identifying problems shows that, there are still many students, who will contract Computer Music courses, do not understand how to operate the DAW. Meanwhile, a small number of others already understand with a moderate skill level. Based on this data, the researchers compiled a design about the basics of using DAW as a medium for expressing musical ideas, so that it is in line with the semester learning plan. In the semester learning plan, the topic of discussion for each meeting is more directed at how to operate the DAW, while the speakers have another view, namely to develop the topic of discussion to become, ways to process and manage music attributes on song arrangements using DAW. The purpose of this development is to bring up the musical aspects of the technical aspects of how to use DAW.

One of the subjects contained in the previous version of the semester learning plan is operationalizing certain features contained in the DAW. Then this editorial team was developed on the new version of the semester learning plan, arrange song arrangement concepts using the features contained in the DAW. As for understanding the concept of the arrangement referred to here, covers various aspects in a musical arrangement, namely, techniques for composing melodic sentences, musical articulation and ornamentation, types, styles, musical genres, etc.

\section{Design Testing and Refinement}

The design testing implementation is carried out at the first meeting. Researchers first explain various things related to the Computer Music course, namely regarding the objectives of the course, the process to be taken at each meeting, and minimum specifications regarding hardware and software that students must have. An explanation of the implementation of the independent learning design was carried out afterwards.

Independent learning designs are conveyed to students in collective discussion in order to obtain understanding, ability, efficiency, and connectedness towards courses. In the end, the discussion resulted in a refinement design regarding selflearning that will be carried out by students is an approach towards the final project of the course. The final assignment for his lecture is to make song rearrangements using DAW.

The independent learning design is prepared with work steps consisting of, (1) self-evaluation and monitoring, (2) goal setting and strategic planning, (3) strategy implementation monitoring, and (4) strategy outcome monitoring. Each point is directed at the stages of making arrangements using DAW by adapting the ideas offered by Sanjaya [12], which consists of the drafting stage, the initial arrangement stage, the arrangement development stage adds new ideas, stage of preparation of further arrangements, and stage of evaluation and revision. As a test design, drealm four 
weeks in the first month, students are asked to fill out worksheets and write down their important notes about the process that has been taken. This worksheet and notes will be created as materials for reflection and evaluation of design improvements.

\section{E. Reflection, Evaluation, and Revision}

Reflection and evaluation of the first phase of activity is directed at the questions, does the independent learning design implemented by students increase efficiency towards proses making song arrangements using DAW? or vice versa?. In an effort to determine the impact of the design implementation, data collection was carried out through a questionnaire. Based on the collected questionnaires, it is found that, during the first four weeks, the work steps carried out by students are quite varied. Although the guidelines for the self-learning work steps are the same, however, every student has different ways of working. This seems to be in line with Gagne [11] that the talents and gifted that each student has affects the way they learn, then they will naturally seek and find ways that are considered effective and efficient.

Based on discussions with practitioner resource persons, the results of activity reflections in the first four weeks, no need to revise the design. We consider that the process that has been carried out is the first stage of design implementation. The second stage is carried out for the next four weeks, namely at the fifth to eighth meeting, according to the course schedule. At the eighth meeting, the activity was filled with midterm examinations, so it was considered appropriate for reflection and evaluation.

\section{F. Trial and Reflection $2^{\text {nd }}$ Phase}

The activity in second phase is an effort to assess design stability. The design implemented is still the same as the previous design, at the first stage. After passing the fifth, sixth and seventh meeting, then at the eighth meeting, a midterm exam was conducted, as well as reflecting and evaluating the second phase design implementation activities.

The results of reflections and collaborative discussions, as well as an assessment of the questionnaire, show that, students are more open and understand about work steps to achieve goals, also in the face of obstacles. The efforts that have been shown are bearing the expected results, namely the ability of students to compile initial arrangements, done by exploring DAW features in order to obtain the musical context they want in their work. Their willingness and ability to explore is the result of their activities to find information independently through online media and ask their colleagues.

The independent learning design in the Computer Music course has had an impact on changing students' ways of thinking and acting in completing their assignments. This also has an impact on the perspective of students on several subjects other than Computer Music. The clarity of the lecturer in conveying topics of discussion, examples of work results, openness and warm communication that is built has motivated students to focus and be active in showing performance. So it can be said that the success of these processes is not based solely on their good design, however, the proficiency of the lecturers and the willingness of students to work together contributed strongly.

\section{G. Final : Design Implementation}

Referring to the data obtained from the implementation of the first and second stages of the design, internally the researchers and collaborators agree that this design is valid. The reason for doing the validity internally is a review of the context, where the scope of implementation is limited, also at a limited time. In other words, even though this design is said to be successful, if it is implemented on a different subject, object, space and time, it is necessary to retry it.

The final stage of implementation is carried out for eight meetings, from nine to sixteen meetings. This implemented design is not included in the course assessment. However, it is more of a kind of guideline in order to improve work ethic in order to achieve good grades. At each meeting, before presenting achievements regarding the extent to which the arrangements have been made, the lecturer first invites students to have a brief discussion about the aspects of self- learning that they have implemented. Among other things, how do you do self-evaluation and monitoring, what you strive for goal setting and strategic planning, how is the strategy implementation monitoring, and what efforts do you make in the strategy outcome monitoring.

After briefly explaining the implementation of their selflearning, the students then presented their music arrangement work. For students who are accustomed to implementing independent learning design patterns optimally, although they work differently, will show a good arrangement work. Between an explanation of the work steps of processing musical aspects, and an explanation of the processing of DAW features, it can be seen from the presentation of the work they deliver.

\section{CONCLUSION}

This self- learning design is carried out as a strengthening of the Computer Music lecture process. The reinforcement is based on the principle of completeness in learning. These aspects of self-learning refer to the final goal, and the objectives of each subject matter of the course. The end goal or the long-term goal is to be able to create musical rearance works, while the short-term goal is to be able to develop musical attributes by optimizing DAW features.

The success of this independent learning process cannot be separated from the enthusiasm in students in developing their knowledge and abilities. The arrangement works that students present can be said to be out of the box from the original work, this is viewed from the processing of musical forms and patterns, types, styles, genres, as well as in terms of sound arrangement. The impact of the implementation of this 
independent learning design is that students are not only able to motivate themselves and manage time. But it also has an impact on awareness and courage to show ability in their own way, and being able to interact in order to obtain the information needed to achieve goals.

\section{ACKNOWLEDGMENT}

This research is an independent research. This research was conducted as an effort for researchers to develop performance and expertise in the field of research, and to develop performance and expertise in education.

Thank you for the support and opportunities given by the Department of Music Education - Faculty of Art and Design Education Universitas Pendidikan Indonesia, and also thank you for the cooperation shown by students and practitioner speakers.

\section{REFERENCES}

[1] X. Guo, "The Application And Research Of Computer MIDI Technology In Music Education" in International Conference on Social Science and Technology Education p. 236-241. 2015.

[2] S. Nart, "Music Software In The Technology Integrated Music Education" Turkish Online J. Educ. Technol. 15, 2 p. 78-84. 2016.

[3] I Arici, "Computer-Assisted Music Teaching In Music Teacher Education Departements: Marmara University Sample Educ". Policy Anal. Strateg. Reaserch 13, 1 p. 71-80. 2018.

[4] I.K. Suardana, "Implementasi Belajar Mandiri Untuk Meningkatkan Aktivitas, Hasil, dan Kemandirian Belajar Mahasiswa" J. Pendidik. dan Pengajaran 45, 1 p. 56-65. 2012.
[5] L.A. Ludovico, G.R. Mangione, "Self Regulation Competence In Music Education" in International Conference e-Learning p. 46-54. 2014.

[6] N.D. Sukmono, "Metode Pembelajaran Self Directed Learning Berbasis ICT Dengan Pemanfaatan Game Android Berkarakter Untuk Pembelajaran Bahasa Indonesia" in Seminar Nasional Pendidikan Bahasa Indonesia p. 247-254. 2015.

[7] I.S. Saripah, "Implementasi Model Pembelajaran Mandiri Program Pendidikan Kecakapan Hidup Perempuan" J. Pendidik. dan Pemberdaya. Masy. 3, 2 p. 176-186. 2016.

[8] F. Cipta, Departemen Pendidikan Seni Musik - FPSD Universitas Pendidikan Indonesia 2, 2 p. 1-17. 2016.

[9] B.S. Bloom, "The New Direction in Educational Research: Alternate Variables" J. Negro Educ. 49, 3 p. 337-349. 1980.

[10] E.E. Gordon, Learning Sequences In Music: Skill, Content, And Patterns Chicago: GIA Publications Inc. 1980.

[11] F. Gagné, Constructs and Models Pertaining to Exceptional Human Abilities, in International Handbook of Research and Development of Giftedness and Talent, 1993.

[12] R.M.S. Sanjaya, Metode Lima Langkah Aransemen Musik Promusika. 2013.

[13] T.L. Gie, Cara Belajar Yang Efisien Yogyakarta: PUBIB, 2002.

[14] M.H. Dembo, Motivation And Learning Strategies For College Success - A Self Management Approach New Jersey: Lawrence Erlbaum Associates, Inc. 2004.

[15] A.H. Alghamdi, Adapting design-based research as a research methodology in educational settings Int. J. Educ. Res. 1, 10 p. 1-12. 2013.

[16] J. Herrington and T.C. Reeves, Using design principles to improve pedagogical practice and promote student engagement in ASCILITE 2011 - The Australasian Society for Computers in Learning in Tertiary Education, 